\title{
Enhancement of radiation sensitivity, delay of proliferative recovery after radiation and abrogation of MAPK (p44/42) signaling by imatinib in glioblastoma cells
}

\author{
QUINCY A. QUICK and DAVID A. GEWIRTZ \\ Department of Pharmacology and Toxicology and Massey Cancer Center, \\ Virginia Commonwealth University, Richmond, VA 23298, USA
}

Received January 27, 2006; Accepted March 24, 2006

\begin{abstract}
Glioblastomas are intrinsically resistant to conventional radiation therapy. The present study investigated the possibility that the tyrosine kinase inhibitor, imatinib, could enhance radiation sensitivity and influence proliferative recovery after irradiation in glioblastoma cells. Radiosensitivity was evaluated by clonogenic survival; apoptotic cell death was evaluated using flow cytometric analysis; proliferative recovery was monitored based on viable cell number subsequent to radiation-induced growth arrest; activation of p44/42 MAPK was based on phosphorylation of the protein. Glioblastoma cells pretreated with imatinib demonstrated an enhanced sensitivity to radiation. Imatinib also delayed proliferative recovery in irradiated glioblastoma cells. Imatinib promoted suppression of p44/42 MAPK signaling both when added prior to and postirradiation. Increased sensitivity to radiation and delayed proliferative recovery in irradiated glioblastoma cells exposed to imatinib may be a consequence of the capacity of imatinib to interfere with p44/42 MAPK kinase signaling. Imatinib may prove to have clinical utility as a neoadjuvant and adjuvant in the treatment of glioblastomas that receive radiation therapy.
\end{abstract}

\section{Introduction}

Glioblastomas are among the most difficult types of central nervous system cancers to treat both because of the rapid progression of this disease, and its frequent resistance to conventional chemotherapy and radiotherapy. This resistance is due, in large part, to the overexpression of receptor tyrosine kinases, such as the epidermal growth factor receptor (EGFR) (1), which has been shown to be activated in glioblastoma cells along with its downstream pro-survival effectors in response to radiation (2). These signaling pathways are also likely to be responsible for the relative refractoriness of this malignancy to apoptotic cell death $(3,4)$.

Correspondence to: Dr David A. Gewirtz, Department of Medicine, Virginia Commonwealth University, P.O. Box 980230, Richmond, VA 23298, USA

E-mail: gewirtz@hsc.vcu.edu

Key words: glioblastoma, radiation, imatinib, MAPK
One approach to modulate the responsiveness of malignancies to radiation is to target molecules that are involved in intracellular signaling events that confer radio-resistance $(5,6)$. In this context, a recent study utilized Iressa, a small molecule tyrosine kinase inhibitor of the EGFR pathway, to radiosensitize glioblastoma cells (7). For the current study we investigated the efficacy of the small molecule tyrosine kinase inhibitor, imatinib (STI-571, Gleevec), an agent which has proven clinically effective in the treatment of chronic myeloid leukemia and gastrointestinal stromal tumors (8-10), to enhance radiation sensitivity and attenuate proliferative recovery in glioblastoma cells. Our studies were performed using a clinically relevant concentration of imatinib $(1 \mu \mathrm{M})$ and fractioned doses of radiation to more closely simulate the clinical treatment of glioblastoma. In addition, we assessed the ability of imatinib to interfere with MAPK signaling.

\section{Materials and methods}

Cells and incubation conditions. T98 and U87 cells were purchased from the American Type Culture Collection, Manassas, VA. GEPE primary glioblastoma cells established from patient tumor explants were provided by Dr William Broaddus (Virginia Commonwealth University School of Medicine). All cell lines were maintained in DMEM containing 10\% FBS, 2 mM L-glutamine, $100 \mathrm{nM}$ MEM, non-essential amino acids, and penicillin-streptomycin at $37^{\circ} \mathrm{C}$ and $5 \%$ $\mathrm{CO}_{2}$.

Western blotting. Cells were plated in DMEM containing $0.5 \% \mathrm{FBS}$, pretreated with $1 \mu \mathrm{M}$ imatinib for $24 \mathrm{~h}$, irradiated (1x2 Gy), and allowed to incubate for 30 or $60 \mathrm{~min}$. Cells were lysed in $60 \mathrm{mM}$ Tris, $\mathrm{pH} 6.8,2 \%$ SDS, and protein content determined using the Lowry method. Samples were electrophoresed in a $10 \%$ polyacrylamide gel, transferred to nitrocellulose membranes and immunoblotted with antibodies against p-p44/42 MAPK (Cell Signaling). Signals were detected using a horseradish peroxidase conjugated secondary antibody and chemiluminescent detection system.

FACS analysis. Cells were plated and irradiated as indicated above, trypsinized at selected time points, rinsed with PBS and stained overnight at $4{ }^{\circ} \mathrm{C}$ in a fluorochrome solution containing propidium iodide $(0.5 \mathrm{mg} / \mathrm{ml}), 0.0038 \mathrm{M} \mathrm{Na}$ 

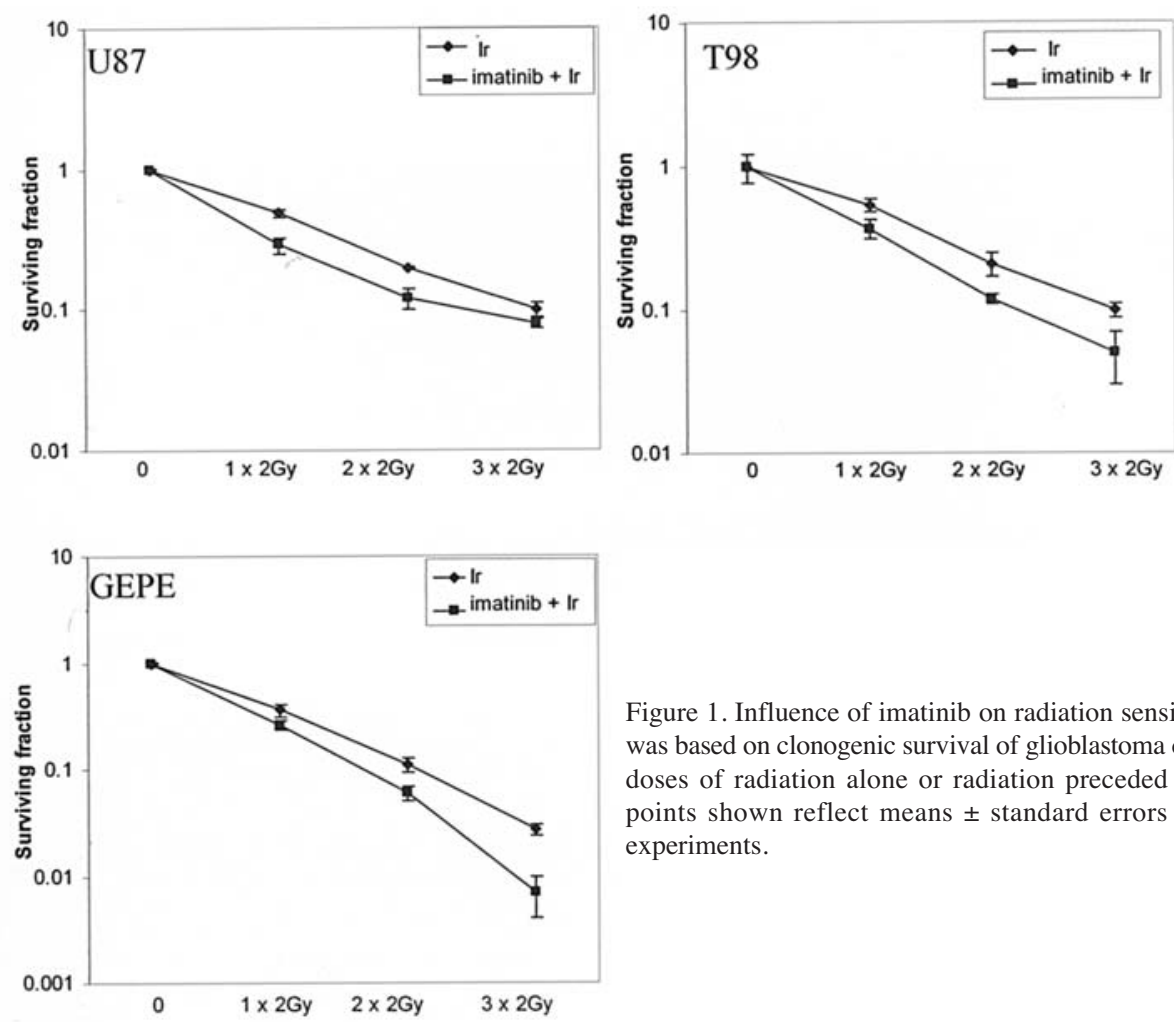

Figure 1. Influence of imatinib on radiation sensitivity. Radiation sensitivity was based on clonogenic survival of glioblastoma cells exposed to fractionated doses of radiation alone or radiation preceded by imatinib $(1 \mu \mathrm{M})$. Data points shown reflect means \pm standard errors for one of three replicate experiments.

citrate, $0.1 \%$ Triton X-100, and RNAse B (7 k units/ml). Flow cytometry analysis was performed on a Coulter Epics XL-MCL using BeckmanCoulter Expo32 software for analysis.

Immunoflourescence labeling. Cells were grown overnight in 24- or 12-well plates, pretreated with $1 \mu \mathrm{M}$ imatinib for $24 \mathrm{~h}$, irradiated $(1 \times 2 \mathrm{~Gy})$, and allowed to incubate for 1 or $24 \mathrm{~h}$. Cells were rinsed twice in phosphate-buffered saline (PBS), and fixed in $4 \%$ paraformaldehyde for $10 \mathrm{~min}$ at room temperature. Cells were then rinsed three times in PBS and blocked with $3.0 \%$ bovine serum albumin, $5 \%$ horse serum, and $0.1 \%$ Triton X-100 in PBS for $1 \mathrm{~h}$ at room temperature. Cells were incubated overnight at $4^{\circ} \mathrm{C}$ with 53BP1 (1:20) antibody in $1 \% \mathrm{BSA} / \mathrm{PBS}$, rinsed three times with PBS, incubated with an Alexa 488 goat anti-mouse conjugated secondary antibody for $1 \mathrm{~h}$ in the dark, rinsed three times and examined with an Olympus IX-70 fluorescent microscope.

Clonogenic survival. Cells were plated and either exposed to radiation alone (fractionated doses of 1x2 Gy, 2x2 Gy and $3 \times 2$ Gy administered at intervals of $6 \mathrm{~h}$ ) or treated for $24 \mathrm{~h}$ with $1 \mu \mathrm{M}$ imatinib prior to radiation, and allowed to incubate at $37^{\circ} \mathrm{C}$ for 10 days. At the termination of the incubation period, cells were fixed with absolute methanol, stained with $1 \%$ crystal violet for $10 \mathrm{~min}$, rinsed in tap water and allowed to dry. Colonies, consisting of $>50$ cells, were then counted to determine surviving fraction. Plating efficiency (PE) was normalized by the formula: ( $\mathrm{PE}=$ average number of cells in control/number of cells plated). The sensitizer enhancement ratio (SER) was calculated by dividing the radiation dose that resulted in a $10 \%$ surviving fraction with radiation alone by the radiation dose resulting in the same survival fraction after treatment with imatinib.
Determination of viable cell number by trypan blue dye exclusion. Cells were plated, exposed to fractionated doses of radiation $(5 \times 2 \mathrm{~Gy})$ over a period of two days with doses administered at approximately 8 a.m., 2 p.m., and 8 p.m. each day, and allowed to incubate for $2,4,6$, and 8 days at $37^{\circ} \mathrm{C}$. Cells were trypsinized from a monolayer culture with $0.25 \%$ trypsin, centrifuged, and resuspended in media or PBS. Cell suspension $(50 \mu 1)$ were mixed with $50 \mu 1$ of trypan-blue and counted using a hemacytometer.

\section{Results}

Influence of imatinib on radiation sensitivity of glioblastoma cells. Due to the overexpression and activation of various tyrosine kinases in glioblastomas (1,11-13), a number of laboratories have investigated the use of tyrosine kinase inhibitors as potential chemotherapeutic agents for this disease (14-16). To evaluate the influence of imatinib on the radiation response, U87, T98, and GEPE glioblastoma cells (the latter derived from patient explants) were exposed to a clinically relevant concentration of imatinib $(1 \mu \mathrm{M})$ for $24 \mathrm{~h}$ prior to irradiation; cells were then permitted to incubate for 10-14 days to determine reproductive integrity via clonogenic survival. Imatinib $(1 \mu \mathrm{M})$ alone did not significantly alter clonogenic survival (data not shown). Fig. 1 indicates that imatinib did enhance the radiation sensitivity in these three cell lines; the effect was consistent over the three radiation doses in the T98 and GEPE cells, but was not evident at the highest dose in U87 cells. The sensitizer enhancement ratio produced by imatinib was $~ 1.5$ in U87 and T98 cells, and 1.25 in GEPE cells.

Absence of apoptotic cell death in glioblastoma cells treated with imatinib and radiation. Flow cytometric analysis was 
Table I. Sub-G $\mathrm{G}_{0}$ cell population in T98 and U87 glioblastoma cells.

\begin{tabular}{|c|c|c|c|c|c|c|c|}
\hline \multicolumn{4}{|c|}{ T98 } & \multicolumn{4}{|c|}{ U87 } \\
\hline $1 x 2 \mathrm{~Gy}$ & Imatinib & Imatinib + 1x2 Gy & $\mathrm{h}$ & $1 x 2 \mathrm{~Gy}$ & Imatinib & Imatinib + 1x2 Gy & $\mathrm{h}$ \\
\hline $1.91 \pm 0.31$ & $3.67 \pm 0.25$ & $1.85 \pm 0.38$ & 24 & $1.99 \pm 0.28$ & $1.90 \pm 0.12$ & $2.06 \pm 0.15$ & 24 \\
\hline $2.05 \pm 0.25$ & $2.73 \pm 0.43$ & $1.91 \pm 0.15$ & 48 & $1.86 \pm 0.09$ & $1.56 \pm 0.005$ & $1.28 \pm 0.11$ & 48 \\
\hline $2.15 \pm 0.27$ & $3.67 \pm 0.19$ & $3.16 \pm 0.33$ & 72 & $2.18 \pm 0.61$ & $1.89 \pm 0.075$ & $1.66 \pm 0.07$ & 72 \\
\hline
\end{tabular}

Assessment of the sub- $\mathrm{G}_{0}$ population in T98 and U87 glioblastoma cells. Cells were either irradiated (2 Gy), treated with imatinib alone $(1 \mu \mathrm{M})$ or treated with imatinib prior to irradiation. Cells were allowed to incubate for 24,48 , and $72 \mathrm{~h}$, and stained with propidium iodide for flow cytometric analysis.

A

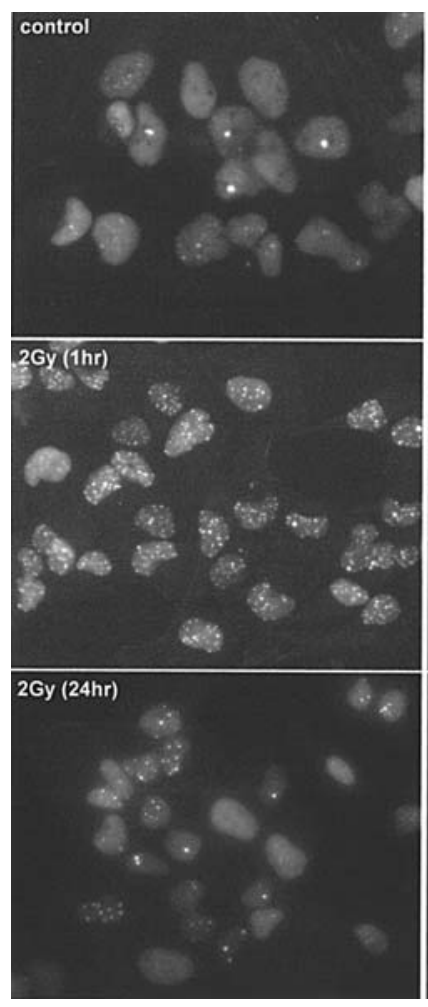

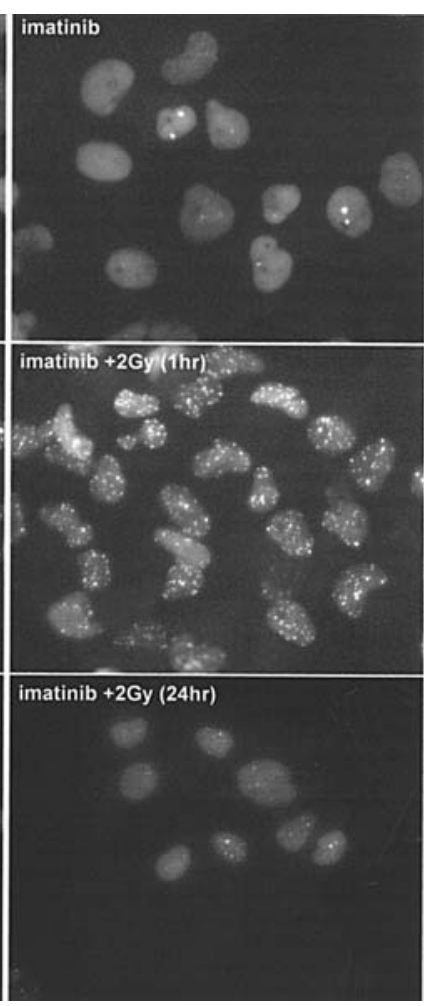

B

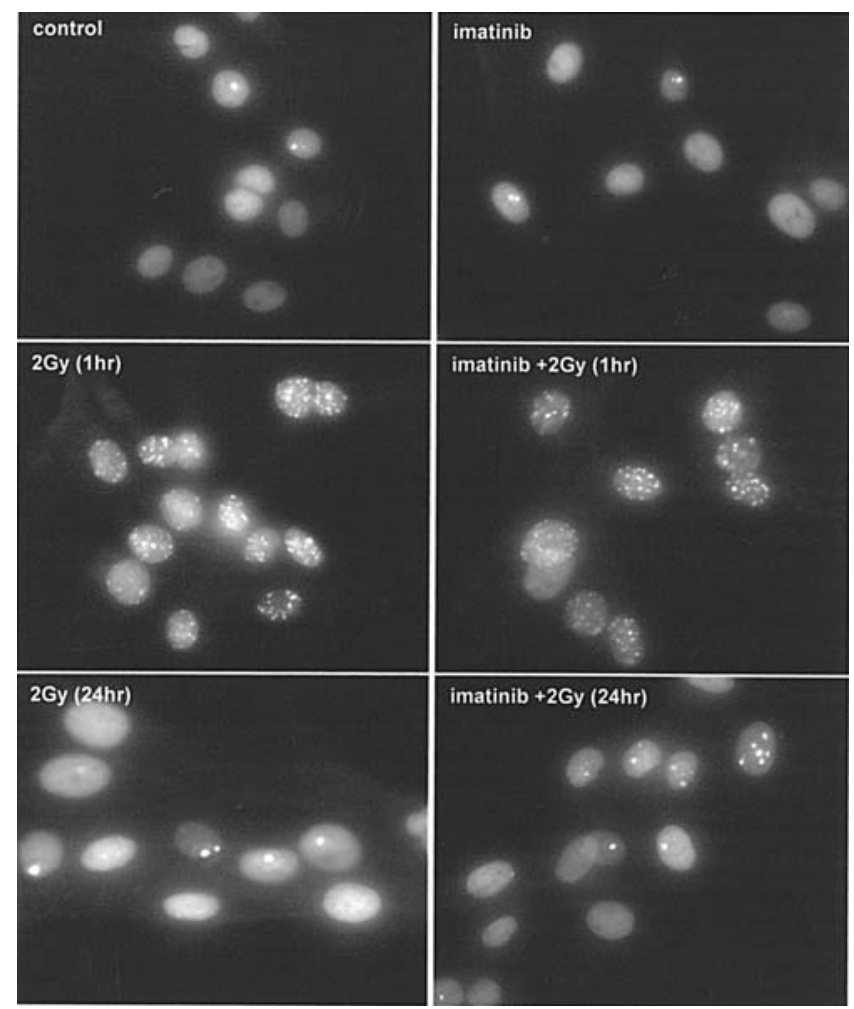

Figure 2. Influence of imatinib on 53BP1 foci formation. 53BP1 foci formation was determined in T98 glioblastoma cells (A) and U87 glioblastoma cells (B) after radiation alone or radiation preceded by imatinib $(1 \mu \mathrm{M})$. Data shown are representative of duplicate experiments.

utilized to determine whether imatinib promoted apoptotic cell death in response to radiation, based on the generation of a sub- $\mathrm{G}_{0}$ cell population. T98 and U87 cells were pretreated with $1 \mu \mathrm{M}$ imatinib, irradiated ( $2 \mathrm{~Gy}$ ), and allowed to incubate for 24,48 , and $72 \mathrm{~h}$. Table I indicates that treatment with imatinib prior to radiation resulted in sub- $\mathrm{G}_{0}$ cell populations comprising $3.16 \pm 0.33 \%$ and $1.66 \pm 0.07 \%$ of the T98 and U87 cells at $72 \mathrm{~h}$, respectively. These values were not significantly different from the percentage of apoptotic cells with radiation alone, $2.15 \pm 0.27 \%$ and $2.18 \pm 0.61 \%$, respectively. Hoechst dye labeling to detect irregularly stained nuclei resulting from chromatin condensation and nuclear fragmentation confirmed the absence of apoptosis (data not shown).
DNA damage-based expression of 53BP1 in irradiated glioblastoma cells. One possible mechanism for modulation of radiation sensitivity in glioblastoma cells is through an increase in DNA damage $(17,18)$. We therefore examined the influence of imatinib on DNA double strand break induction based on the development of 53BP1 foci (19-21). T98 and U87 cells were pretreated with imatinib $(1 \mu \mathrm{M})$, irradiated ( $2 \mathrm{~Gy}$ ), and allowed to incubate for one hour. Immunoflourescence analysis indicated the rapid induction of nuclear 53BP1 foci, an indication of DNA damage, in T98 (Fig. 2A) and U87 (Fig. 2B) glioblastoma cells that received radiation alone or imatinib prior to irradiation. Glioblastoma cells treated with imatinib alone did not display nuclear 53BP1 
Table II. 53BP1 foci expression in glioblastoma cells.

\begin{tabular}{lcr}
\hline & T98 & U87 \\
\hline Control & $5 \pm 1$ & $0 \pm 0$ \\
2 Gy $(1$ h) & $87 \pm 13$ & $84 \pm 0$ \\
Imatinib + 2 Gy (1 h) & $83 \pm 5$ & $79 \pm 2$ \\
2 Gy (24 h) & $15 \pm 3$ & $1 \pm 1$ \\
Imatinib + 2 Gy (24 h) & $15 \pm 0$ & $1 \pm 1$
\end{tabular}

Measure of DNA damage as determined by 53BP1 foci in T98 and U87 cells. Cells were either irradiated ( $2 \mathrm{~Gy}$ ), treated with imatinib alone $(1 \mu \mathrm{M})$ or treated with imatinib prior to irradiation and allowed to incubate for $1 \mathrm{~h}$ or $24 \mathrm{~h}$. Data shown are representative of duplicate experiments in which at least 75 cells were counted. Cells containing $>6$ foci/cell were considered to be 53BP1 positive. Values presented indicate the percentage of cells that were positive for 53BP1 foci.

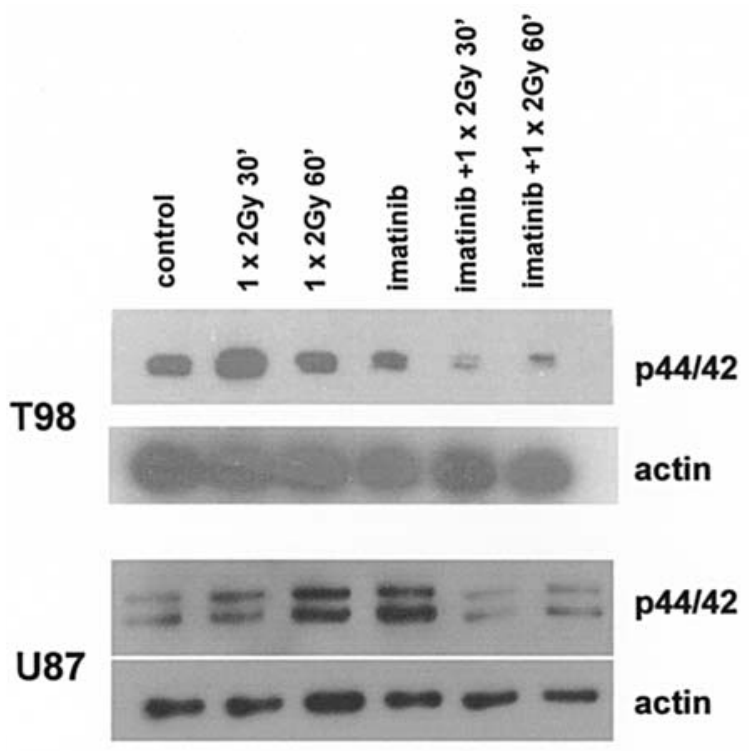

Figure 3. Influence of imatinib on activation of p44/42 MAPK. Activation of p-44/42MAPK by radiation alone and radiation preceded by imatinib was assessed based on phosphorylation of the protein using a phosphospecific antibody. Data shown are representative of three independent experiments.

foci expression. There was no evident increase in 53BP foci when the cells were pretreated with imatinib prior to irradiation. A decrease in 53BP1 foci was observed at $24 \mathrm{~h}$ in T98 and U87 glioblastoma cells that were exposed to radiation alone or pretreated with imatinib prior to radiation exposure (Fig. 2), which is likely to be indicative of the rapid repair of DNA double-strand breaks. However, there was no apparent difference in the overall decline of 53BP1 foci with radiation alone versus radiation preceded by imatinib treatment (Table II).

Suppression of MAPK by imatinib. One critical signaling element that protects glioblastoma cells from cell death is signaling through MAPK $(22,23)$. We evaluated the influence of radiation alone and radiation preceded by imatinib on the expression of p-p44/42 MAPK in T98 and U87 cells. Time-

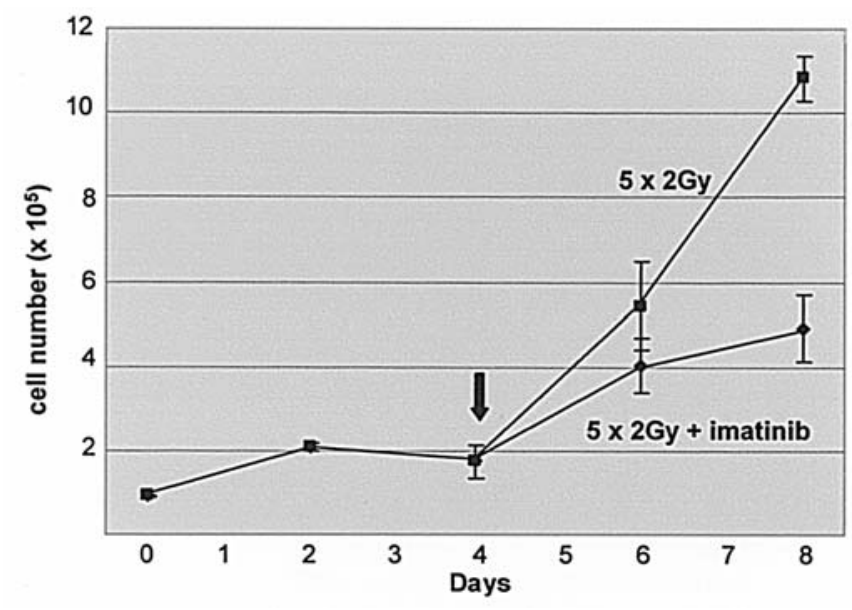

Figure 4. Delayed proliferative recovery of glioblastoma cells treated with imatinib post-irradiation. Cells were irradiated $(5 \times 2 \mathrm{~Gy})$ and monitored for a period of 8 days. At day 4 post irradiation, cells were exposed either to solvent (DMSO) or imatinib $(1 \mu \mathrm{M})$. Arrow indicates time of solvent or imatinib treatment. Data points shown reflect means \pm standard errors for one of three independent experiments.

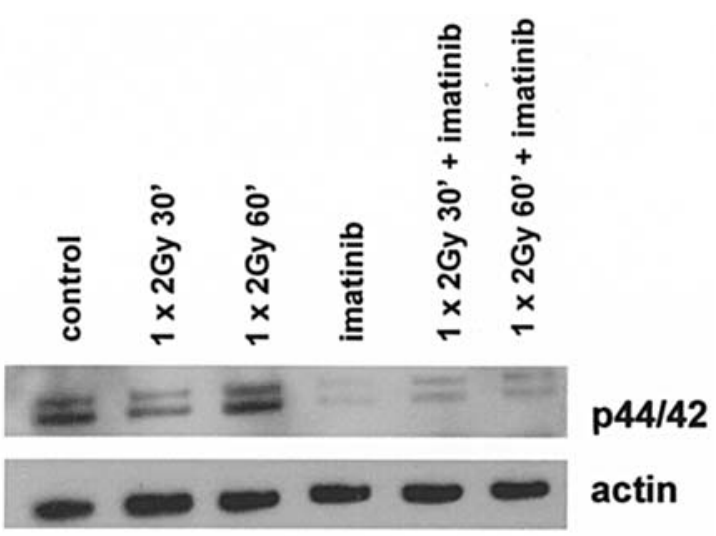

Figure 5. Activation of p-p44/42 MAPK in glioblastoma cells treated with imatinib post-irradiation. Data shown are representative of duplicate experiments.

course experiments revealed maximal induction of p-p44/42 MAPK with radiation alone (1x2 Gy) at $30 \mathrm{~min}$ and $1 \mathrm{~h}$ in T98 and U87 cells, respectively, an effect that was suppressed by pretreatment with imatinib (Fig. 3). However, we did not observe an induction of p-p44/42 MAPK in irradiated GEPE primary glioblastoma cells (data not shown). Endogenous expression of p38 MAPK or radiation induced activation of p-JNK was not detected in glioblastoma cells (data not shown).

Imatinib delays proliferative recovery of glioblastoma cells. In previous studies, we determined that T98 glioblastoma cells exposed to ionizing radiation undergo a prolonged senescence-like arrest followed by proliferative recovery (24). As proliferative recovery may reflect tumor recurrence or regrowth after radiation therapy, we were interested in whether imatinib might block proliferative recovery of irradiated glioblastoma cells. T98 glioblastoma cells were plated, exposed to sublethal doses of fractionated radiation $(5 \times 2 \mathrm{~Gy})$ and allowed to incubate for 4 days prior to treatment 
with imatinib $(1 \mu \mathrm{M})$. Fig. 5 indicates that with radiation alone, a two-day transient growth arrest was followed by proliferative recovery. Treatment with imatinib significantly $(\mathrm{p}<0.05)$ attenuated the rate of recovery (Fig. 4). To assess if interference with p44/42 MAPK could be involved in delaying proliferative recovery of irradiated T98 cells, we monitored the levels of p-p44/42 MAPK in T98 cells, which were irradiated and subsequently treated with imatinib. The induction of p-p44/42 MAPK by radiation at $1 \mathrm{~h}$ was suppressed by treatment with imatinib (Fig. 5).

\section{Discussion}

The overexpression and amplification of tyrosine kinases have been implicated in the resistance of glioblastomas to chemotherapy and radiation therapy, via downstream activation of pro-survival signaling cascades $(1,14,25-27)$. Here we show that a clinically relevant concentration of imatinib $(1 \mu \mathrm{M})$, a small molecule tyrosine kinase inhibitor, was able to confer enhanced radiation sensitivity to glioblastoma cells. These data are consistent with previous investigations that have demonstrated that tyrosine kinase inhibitors increase the radiosensitivity of breast, prostate, and glioblastoma cells (28-32).

Interestingly, we did not observe apoptotic cell death in glioblastoma cells exposed to either radiation alone or with imatinib pretreatment, despite significant effects on clonogenic survival. In a related study, Beppu et al (33) indicated that neuroblastoma cells required significantly elevated concentrations of imatinib (well above those that would be clinically relevant) to induce apoptosis. Our findings are also consistent with previous reports that have demonstrated a lack of apoptotic cell death in glioblastoma cells that either received high doses of radiation $(>20 \mathrm{~Gy})(3,4)$ or were pretreated with other sensitizing agents prior to irradiation $(34,35)$.

Our studies indicate that the effect of imatinib is unlikely to be occurring through either an increase in the induction or repair of double strand breaks in DNA, based on comparative levels of nuclear 53BP1 foci expression observed in glioblastoma cells exposed to radiation alone and glioblastoma cells pretreated with imatinib. Our studies strongly suggest that the effects of imatinib are cytostatic and are related to interference with activation of MAP kinase. Consistent with previous findings in prostate tumor cells as well as other glioblastoma cells $(28,34,26)$, we observe the activation of p44/42 MAPK expression by radiation, which was abrogated when irradiated glioblastoma cells were pretreated with imatinib. This observation supports the findings of Beppu et al (33) which also demonstrated downregulation of p-p44/42 MAPK expression in neuroblastoma cells treated with imatinib after stimulation with PDGF-BB.

In studies performed by Holdoff et al (29) and Russell et al (32), the radiosensitizing effects of imatinib in other glioblastoma cells were attributed to antagonism of PDGFR signaling and DNA repair, respectively. However, imatinib failed to down regulate p-PDGFRß in any of the three glioblastoma cell lines (not shown). The differences between our current findings relating to effects on MAP kinase and the work by other investigators can be attributed, in part, to our use of a clinically relevant concentration of imatinib $(1 \mu \mathrm{M})$, and heterogeneity between cellular systems. Additionally it is entirely possible that imatinib has pleiotropic effects on PDGFR signaling and DNA repair, particularly at elevated drug concentrations. These pleiotropic effects may explain why we did not detect alterations at the level of MAP kinase in the human tumor cell explants, as sensitization may reflect the impact of imatinib on other cytoprotective pathways.

The finding that may prove to have the greatest significance is that imatinib has the capacity to block proliferative recovery of glioblastoma cells exposed to clinically relevant doses of fractionated radiation, as one critical element in the resistance of glioblastomas to radiotherapy is their high rates of recurrence. Taken together, these experiments suggest that imatinib can not only be an effective neoadjuvant pharmacological agent in glioblastoma cells by abrogating mitogenic signaling and enhancing radiation sensitivity, but also may be a potentially useful adjuvant agent to be used against recurring glioblastomas resistant to radiotherapy.

\section{Acknowledgements}

We are grateful to Dr Thanos Halazonetis for providing us with the antibody to 53BP1 as described in ref. 20 .

\section{References}

1. Barker FG II, Simmons ML, Chang SM, Prados MD, Larson DA, Sneed PK, Wara WM, Berger MS, Chen P, Israel MA and Aldape KD: EGFR overexpression and radiation response in glioblastoma multiforme. Int J Radiat Oncol Biol Phys 51: 410-418, 2001.

2. Lammering G, Hewit TH, Hawkins WT, Contessa JN, Reardon DB, Lin PS, Valerie K, Dent P, Mikkelsen RB and Schmidt-Ullrich RK: Epidermal growth factor receptor as a genetic therapy target for carcinoma cell radiosensitization. J Natl Cancer Inst 93: 921-929, 2001.

3. Haas-Kogan DA, Kogan SS, Yount G, Hsu J, Haas M, Deen DF and Israel MA: p53 function influences the effect of fractionated radiotherapy on glioblastoma tumors. Int J Radiat Oncol Biol Phys 43: 399-403, 1999.

4. Yao KC, Komata T, Kondo Y, Kanzawa T, Kondo S and Germano IM: Molecular response of human glioblastoma multiforme cells to ionizing radiation: cell cycle arrest, modulation of the expression of cyclin-dependent kinase inhibitors, and autophagy. J Neurosurg 98: 378-384, 2003

5. Tremont-Lukats IW and Gilbert MR: Advances in molecular therapies in patients with brain tumors. Cancer Control 10: 125-137, 2003.

6. Kondo Y, Hollingsworth EF and Kondo S: Molecular targeting for malignant gliomas. Int J Oncol 24: 1101-1109, 2004.

7. Stea B, Falsey R, Kislin K, Patel J, Glanzberg H, Carey S, Ambrad AA, Meuillet EJ and Martinez JD: Time and dosedependent radiosensitization of the glioblastoma multiforme U251 cells by the EGF receptor tyrosine kinase inhibitor ZD1839 ('Iressa'). Cancer Lett 202: 43-51, 2003.

8. Cohen MH, Johnson JR and Pazdur R: US Food and Drug Administration Drug Approval Summary: conversion of imatinib mesylate (STI571; Gleevec) tablets from accelerated approval to full approval. Clin Cancer Res 11: 12-19, 2005.

9. Kindler T, Breitenbuecher F, Marx A, Beck J, Hess G, Weinkauf B, Duyster J, Peschel C, Kirkpatrick CJ, Theobald M, Gschaidmeier H, Huber C and Fischer T: Efficacy and safety of imatinib in adult patients with c-kit-positive acute myeloid leukemia. Blood 103: 3644-3654, 2004.

10. Maki RG: Gastrointestinal stromal tumors respond to tyrosine kinase-targeted therapy. Curr Treat Options Gastroenterol 7: 13-17, 2004.

11. Fleming TP, Saxena A, Clark WC, Robertson JT, Oldfield EH, Aaronson SA and Ali IU: Amplification and/or overexpression of platelet-derived growth factor receptors and epidermal growth factor receptor in human glial tumors. Cancer Res 52: 4550-4553, 1992. 
12. Hermanson M, Funa K, Koopmann J, Maintz D, Waha A, Westermark B, Heldin CH, Wiestler OD, Louis DN, von Deimling A and Nister M: Association of loss of heterozygosity on chromosome $17 \mathrm{p}$ with high platelet-derived growth factor alpha receptor expression in human malignant gliomas. Cancer Res 56: 164-171, 1996.

13. Watanabe K, Tachibana O, Sata K, Yonekawa Y, Kleihues P and Ohgaki H: Overexpression of the EGF receptor and p53 mutations are mutually exclusive in the evolution of primary and secondary glioblastomas. Brain Pathol 6: 217-223, 1996.

14. Haas-Kogan DA, Prados MD, Tihan T, Eberhard DA, Jelluma N, Arvold ND, Baumber R, Lamborn KR, Kapadia A, Malec M, Berger MS and Stokoe D: Epidermal growth factor receptor, protein kinase B/Akt, and glioma response to erlotinib. J Natl Cancer Inst 97: 880-887, 2005.

15. Kilic T, Alberta JA, Zdunek PR, Acar M, Iannarelli P, O'Reilly T, Buchdunger E, Black PM and Stiles CD: Intracranial inhibition of platelet-derived growth factor-mediated glioblastoma cell growth by an orally active kinase inhibitor of the 2-phenylaminopyrimidine class. Cancer Res 60: 5143-5150, 2000.

16. Lokker NA, Sullivan CM, Hollenbach SJ, Israel MA and Giese NA: Platelet-derived growth factor (PDGF) autocrine signaling regulates survival and mitogenic pathways in glioblastoma cells: evidence that the novel PDGF-C and PDGF-D ligands may play a role in the development of brain tumors. Cancer Res 62: 3729-3735, 2002.

17. Hadjipanayis CG and De Luca NA: Inhibition of DNA repair by a herpes simplex virus vector enhances the radiosensitivity of human glioblastoma cells. Cancer Res 65: 5310-5316, 2005.

18. Hart LS, Yannone SM, Naczki C, Orlando JS, Waters SB, Akman SA, Chen DJ, Ornelles D and Koumenis C: The adenovirus E4orf6 protein inhibits DNA double strand break repair and radiosensitizes human tumor cells in an E1B-55Kindependent manner. J Biol Chem 280: 1474-1481, 2005.

19. Rappold I, Iwabuchi K, Date T and Chen J: Tumor suppressor p53 binding protein 1 (53BP1) is involved in DNA damagesignaling pathways. J Cell Biol 153: 613-620, 2001.

20. Schultz LB, Chehab NH, Malikzay A and Halazonetis TD: p53 binding protein $1(53 \mathrm{BP} 1)$ is an early participant in the cellular response to DNA double-strand breaks. J Cell Biol 151: 1381-1390, 2000.

21. Wang B, Matsuoka S, Carpenter PB and Elledge SJ: 53BP1, a mediator of the DNA damage checkpoint. Science 298: 1435-1438, 2002.

22. Dent P, Jarvis WD, Birrer MJ, Fisher PB, Schmidt-Ullrich RK and Grant S: The roles of signaling by the p42/p44 mitogenactivated protein (MAP) kinase pathway; a potential route to radio- and chemo-sensitization of tumor cells resulting in the induction of apoptosis and loss of clonogenicity. Leukemia 12: 1843-1850, 1998

23. Dent P, Yacoub A, Fisher PB, Hagan MP and Grant S: MAPK pathways in radiation responses. Oncogene 22: 5885-5896, 2003.
24. Quick QA and Gewirtz DA: An accelerated senescence response to radiation in p53 wild-type glioblastoma cells. J Neurosurg (In press).

25. Lal B, Xia S, Abounader R and Laterra J: Targeting the c-Met pathway potentiates glioblastoma responses to gamma-radiation. Clin Cancer Res 11: 4479-4486, 2005

26. Messina S, Leonetti C, De Gregorio G, Affatigato V, Ragona G, Frati L, Zupi G, Santoni A and Porcellini A: Ras inhibition amplifies cisplatin sensitivity of human glioblastoma. Biochem Biophys Res Commun 320: 493-500, 2004.

27. Nakamura JL, Karlsson A, Arvold ND, Gottschalk AR, Pieper RO, Stokoe D and Haas-Kogan DA: PKB/Akt mediates radiosensitization by the signaling inhibitor LY294002 in human malignant gliomas. J Neurooncol 71: 215-222, 2005.

28. Hagan M, Wang L, Hanley JR, Park JS and Dent P: Ionizing radiation-induced mitogen-activated protein (MAP) kinase activation in DU145 prostate carcinoma cells: MAP kinase inhibition enhances radiation-induced cell killing and G2/Mphase arrest. Radiat Res 153: 371-383, 2000.

29. Holdhoff M, Kreuzer KA, Appelt C, Scholz R, Na IK, Hildebrandt B, Riess H, Jordan A, Schmidt CA, van Etten RA, Dorken B and le Coutre P: Imatinib mesylate radiosensitizes human glioblastoma cells through inhibition of platelet-derived growth factor receptor. Blood Cells Mol Dis 34: 181-185, 2005.

30. Lammering G, Hewit TH, Valerie K, Lin PS, Contessa JN and Schmidt-Ullrich RK: Anti-erbB receptor strategy as a gene therapeutic intervention to improve radiotherapy in malignant human tumours. Int J Radiat Biol 79: 561-568, 2003.

31. Liang K, Lu Y, Jin W, Ang KK, Milas L and Fan Z: Sensitization of breast cancer cells to radiation by trastuzumab. Mol Cancer Ther 2: 1113-1120, 2003.

32. Russell JS, Brady K, Burgan WE, Cerra MA, Oswald KA, Camphausen $\mathrm{K}$ and Tofilon PJ: Gleevec-mediated inhibition of Rad51 expression and enhancement of tumor cell radiosensitivity. Cancer Res 63: 7377-7383, 2003.

33. Beppu K, Jaboine J, Merchant MS, Mackall CL and Thiele CJ: Effect of imatinib mesylate on neuroblastoma tumorigenesis and vascular endothelial growth factor expression. J Natl Cancer Inst 96: 46-55, 2004.

34. Chakravarti A, Chakladar A, Delaney MA, Latham DE and Loeffler JS: The epidermal growth factor receptor pathway mediates resistance to sequential administration of radiation and chemotherapy in primary human glioblastoma cells in a RASdependent manner. Cancer Res 62: 4307-4315, 2002.

35. Ostruszka LJ and Shewach DS: The role of cell cycle progression in radiosensitization by 2',2'-difluoro-2'-deoxycytidine. Cancer Res 60: 6080-6088, 2000

36. Park JS, Qiao L, Su ZZ, Hinman D, Willoughby K, McKinstry R, Yacoub A, Duigou GJ, Young CS, Grant S, Hagan MP, Ellis E, Fisher PB and Dent P: Ionizing radiation modulates vascular endothelial growth factor (VEGF) expression through multiple mitogen activated protein kinase dependent pathways. Oncogene 20: 3266-3280, 2001. 